\title{
GAMBARAN PEMELIHARAAN KEBERSIHAN GTL AKRILIK PADA MASYARAKAT KELUHARAN BATU PUTIH BAWAH
}

\author{
${ }^{1}$ Britzman Nikanor Mapanawang \\ ${ }^{2}$ Wulan P. J. Kaunang \\ ${ }^{3}$ Vonny N. S. Wowor
}

\author{
${ }^{1}$ Kandidat Skripsi Program Studi Pendidikan Dokter Gigi Fakultas Kedokteran \\ Universitas Sam Ratulangi Manado \\ ${ }^{2}$ Bagian Ilmu Kesehatan Masyarakat Fakultas Kedokteran Universitas Sam Ratulangi \\ Manado \\ ${ }^{3}$ Program Studi Pendidikan Dokter Gigi Fakultas Kedokteran \\ Universitas Sam Ratulangi Manado \\ E-mail: britzman88@gmail.com
}

\begin{abstract}
Removable acrylic denture is a prosthesis that replaces the natural teeth that is useful to fill the empty space and restore jaw occlusion, phonetics and retain the remaining oral tissues to stay healthy, and can be removed by the patient. This study aimed to describe the maintenance of the removable denture hygiene in communities with 1611 inhabitants in Batu Putih Bawah. This was a descriptive study with 60 samples obtained by using total sampling method. The results showed that there were 19 respondents (31.6\%) had dirty dentures, while 21 respondents (35\%) had very dirty dentures. About $66.6 \%$ of respondents had poor denture hygiene. There were $73.3 \%$ respondents that had never received verbal instructions, and $95 \%$ respondents had never received written instruction about hygiene maintenance after installation. Based on the frequency of cleaning, 95\% respondents mentioned that they cleaned their dentures every day, and as much as $65 \%$ respondents cleaned theirs twice a day. Based on the times of cleaning, 38.3\% respondents cleaned their dentures in the morning and in the afternoon while they took baths and $6.7 \%$ before sleeping at night. All respondents cleaned their dentures with toothpaste or soap. Conclusion: Based on the clinical condition, most of the respondents in Batu Putih Bawah had dirty removable acrylic dentures.
\end{abstract}

Keywords: maintenance of denture hygiene, removable acrylic denture

\begin{abstract}
Abstrak: GTL akrilik adalah alat bantu yang menggantikan gigi asli yang berguna untuk mengisi daerah rahang yang kosong, mengembalikan oklusi dan fonetik, mempertahankan jaringan mulut yang masih ada agar tetap sehat, serta dapat dilepas oleh pasien. Penelitian ini bertujuan untuk mengetahui gambaran pemeliharaan kebersihan GTL akrilik pada masyarakat kelurahan Batu Putih Bawah dengan populasi 1611 jiwa. Penelitian bersifat deskriptif dan pengambilan sampel menggunakan metode total sampling. Sampel berjumlah 60 responden. Instrumen penelitian yang digunakan yakni kuesioner. Hasil penelitian menunjukkan bahwa 19 responden (31,6\%) memiliki gigi tiruan kotor dan 21 responden (35\%) dengan gigi tiruan sangat kotor. Jadi sekitar 66,6\% responden memiliki kebersihan gigi tiruan yang buruk. Hasil penelitian menunjukkan $73,3 \%$ responden pengguna GTL akrilik tidak pernah menerima instruksi secara lisan, dan 95\% responden tidak pernah menerima instruksi dalam bentuk tulisan tentang cara pemeliharaan kebersihan pasca pemasangan. Berdasarkan frekuensi pembersihan 95\% responden mengaku membersihkan GTL akrilik setiap hari, dan 65\% membersihkan GTL akrilik dua kali sehari. Pemeliharaan kebersihan berdasarkan waktu
\end{abstract}


menunjukkan 38,3\% responden membersihkan GTL akrilik sewaktu mandi pagi dan sore hari dan $6,7 \%$ sewaktu sebelum tidur. Berdasarkan cara pembersihan semua responden (100\%) menjawab bahwa mereka membersihkan GTL akrilik menggunakan pasta gigi atau sabun. Simpulan: Berdasarkan hasil penelitian diperoleh umumnya responden di Batu Putih Bawah mempunyai kondisi klinis GTL akrilik yang kotor.

Kata kunci: pemeliharaan kebersihan, GTL akrilik

\section{PENDAHULUAN}

Perkembangan jaman yang semakin maju memberikan dampak yang luas di segala bidang. Kemajuan ilmu pengetahuan dan teknologi terjadi juga pada bidang ilmu kedokteran gigi. Prostodonsia merupakan sebagai salah satu cabang ilmu kedokteran gigi ikut mengalami kemajuan. Prostodonsia merupakan cabang ilmu kedokteran gigi yang dikhususkan untuk perawatan dan pembuatan gigi tiruan. Gigi tiruan dibutuhkan untuk menggantikan gigi asli yang hilang, yang tebagi atas GTC dan GTL. ${ }^{1,2}$

Saat ini beragam pilihan untuk perawatan dan pembuatan gigi tiruan telah tersedia, dan mudah diperoleh masyarakat. Namun hal utama yang menjadi masalah ialah kondisi ekonomi masyarakat itu sendiri. Menurut penelitian sebagian besar atau sekitar 60\% masyarakat Indonesia berada pada tingkat ekonomi menengah ke bawah, hal ini tentunya menjadi faktor penghalang bagi masyarakat dengan ekonomi rendah untuk mendapatkan perawatan Prostodonsia. ${ }^{3}$ Perawatan atau pembuatan gigi tiruan membutuhkan biaya yang relatif mahal bagi sebagian anggota masyarakat, oleh karena itu masyarakat akan memilih perawatan pembuatan gigi tiruan yang membutuhkan biaya yang murah. Menurut penelitian yang dilakukan oleh Magdarina D. A. tentang Presentase Pengguna Protesa di Indonesia pada tahun 2010 menunjukkan bahwa masyarakat pengguna gigi tiruan di indonesia sebanyak $4,5 \%{ }^{4}$

GTL Akrilik memiliki kelebihan utama yaitu warnanya yang mirip jaringan mulut serta harganya yang relatif murah dibandingkan dengan jenis gigi tiruan yang lain. Kekurangannya antara lain yait mudah patah, permukaan basis bi. mengiritasi mukosa mulut, dan permukaar basis akrilik yang tidak bagus atau berpori bisa mengakibatkan penumpukan sisa makanan, sehingga. Apabila kebersihannya kurang terjaga dapat memberikan dampak yang buruk bagi jaringan gigi yang masih tinggal serta mukosa pendukungnya.

Pemakaian GTL Akrilik yang tidak bersih dapat mengakibatkan terjadinya berbagai macam penyakit gigi dan mulut, dikarenakan terjadinya penumpukan sisa makanan yang merupakan predisposisi terjadinya plak pada gigi tiruan. Penyakit yang paling umum terjadi pada pengguna gigi tiruan yang tidak bersih ialah denture stomatitis. Denture Stomatitis atau Denture sore mouth adalah infeksi yang terjadi pada mukosa mulut, hal ini paling sering terjadi pada pengguna GTL lengkap atau penuh dimana mukosa mulut yang tertutupi oleh basis gigi tiruan. Penyebab utama Denture Stomatitis ialah jamur Candida albican yaitu jamur yang paling umum yang terdapat pada rongga mulut, ditandai dengan adanya eritema dibawah gigi tiruan, sariawan pada mukosa mulut serta pembengkakan, dan peradangan. ${ }^{5}$

Pentingnya perawatan setelah pemasangan gigi tiruan, membuat penulis terdorong untuk meneliti tentang gambaran pemeliharaan kebersihan GTL Akrilik pada masyarakat pengguna GTL Akrilik di kelurahan Batu Putih Bawah kecamatan Ranowulu Bitung Utara. Kelurahan Batu Putih Bawah dipilih penulis sebagai lokasi penelitian karena penulis sering berkunjung ke lokasi tersebut. Berdasarkan pengamatan yang penulis lakukan, banyak penduduk yang menggunakan GTL Akrilik namun pemeliharaan kebersihan GTL Akrilik dan kebersihan mulutnya masih sangat kurang. Di samping itu alasan lainnya yaitu masalah ini belum pernah diteliti sebelumnya.

Tujuan dari penelitian ini yaitu untuk memperoleh gambaran tentang 
pemeliharaan kebersihan GTL Akrilik pada masyarakat di Kelurahan Batu Putih Bawah, dengan cara mengetahui distribusi frekuensi subjek penelitian berdasarkan intrusksi lisan dan tulisan tentang cara membersihkan gigi tiruan, mengetahui distribusi frekuensi subjek penelitian berdasarkan frekuensi pembersihan gigi tiruan dalam sehari, mengetahui distribusi frekuensi subjek penelitian berdasarkan waktu pembersihan, mengetahui distribusi frekuensi subjek penelitian berdasarkan cara pembersihan, dan mengetahui distribusi subjek penelitian berdasarkan kondisi kebersihan gigi tiruan.

\section{BAHAN DAN METODE}

Penelitian ini merupakan penelitian deskriptif. Besar sampel yang diteliti berjumlah 60 orang diambil dengan teknik total sampling.

Penelitian dilakukan dengan terlebih dahulu meminta izin untuk melakukan penelitian pada setiap orang yang menjadi subjek penelitian yang dikunjungi.

Pengambilan data dilakukan dengan menggunakan kuesioner yang sudah pernah digunakan sebelumnya ${ }^{6}$, dan diisi oleh subjek penelitian dengan izin surat penelitian yang disertakan bersama kuesioner. Pemberian surat penelitian dan kuesioner kepada subjek penelitian di kelurahan batu putih bawah.

Data yang di dapat kemudian diolah berdasarkan distribusi frekuensi dan disajikan dalam bentuk tabel lalu dianalisis berdasarkan hasil persentase.

\section{HASIL}

\section{Karakteristik Subjek}

Pada penelitian ini subjek penelitian memiliki karakteristik yang dibedakan atas usia, jenis kelamin, tingkat pendidikan. Data yang terkumpul disajikan dalam bentuk tabel berdasarkan hasil penelitian.

Berikut pada Tabel 1 didistribusi frekuensi subjek penelitian berdasarkan usia.

Tabel 1. Distribusi frekuensi subjek penelitian berdasarkan usia.

\begin{tabular}{lcc}
\hline Usia & $\mathrm{n}$ & $\%$ \\
\hline a. 20-39 tahun & 29 & 48,3 \\
b. 40-59 tahun & 26 & 43,3 \\
c. $>60$ tahun & 5 & 8,4 \\
\hline \multicolumn{1}{c}{ Total } & 60 & 100 \\
\hline
\end{tabular}

Dari data pada Tabel 1 di atas terlihat bahwa subjek penelitian dengan usia 20-39 tahun berjumlah 29 orang atau sebesar $48,3 \%$, usia 40-59 tahun berjumlah 26 orang $(43,3 \%)$, dan usia 60 tahun ke atas berjumlah 5 orang $(8,33 \%)$.

Distribusi frekuensi subjek penelitian berdasarkan jenis kelamin, dapat dilihat pada tabel 2 berikut :

Tabel 2. Distribusi frekuensi subjek penelitian berdasarkan jenis kelamin.

\begin{tabular}{lcc}
\hline Jenis kelamin & $\mathrm{n}$ & $\%$ \\
\hline a. Laki-laki & 32 & 53,4 \\
b. Perempuan & 28 & 46,6 \\
\hline \multicolumn{1}{c}{ Total } & 60 & 100 \\
\hline
\end{tabular}

Data Tabel 2 menunjukkan bahwa, jumlah subjek penelitian dengan jenis kelamin laki-laki berjumlah 32 orang $(53,3 \%)$ dan perempuan sebesar 28 orang ( $46,6 \%)$.

Berikut adalah distribusi frekuensi subjek penelitian berdasarkan tingkat pendidikan bisa dilihat pada Tabel 3 berikut ini:

Tabel 3. Distribusi frekuensi subjek penelitian berdasarkan tingkat pendidikan.

\begin{tabular}{lcc}
\hline $\begin{array}{l}\text { Tingkat } \\
\text { pendidikan }\end{array}$ & $\mathrm{n}$ & $\%$ \\
\hline a. Tidak sekolah & 4 & 6,7 \\
b. SD & 18 & 30 \\
c. SLTP & 22 & 36,6 \\
d. SLTA & 12 & 20 \\
e. PT & 4 & 6,7 \\
\hline \multicolumn{1}{c}{ Total } & 60 & 100 \\
\hline
\end{tabular}

Data pada tabel 3 memperlihatkan hasil bahwa subjek yang tidak pernah menempuh jenjang pendidikan atau subjek yang tidak bersekolah berjumlah 4 orang (6,66\%), subjek yang hanya sampai pada tingkat pendidikan sejenjang SD sebanyak 18 orang (30\%), kemudian subjek yang dengan tingkat pendidikan sampai pada jenjang SLTP sebanyak 22 orang (36,6\%), subjek dengan tingkat pendidikan sampai jenjang SLTA sebanyak 12 orang $(20 \%)$, sedangkan subjek yang sampai 
pada tingkat pendidikan Perguruan Tinggi sebanyak 4 orang dengan persentase 6,66\%.

\section{Gambaran hasil penelitian}

Tabel 4 mendistribusikan subjek penelitian berdasarkan jenis gigi tiruan yang digunakan, yakni gigi tiruan satu rahang $(\mathrm{RA} / \mathrm{RB})$ atau gigi tiruan pada kedua rahang (RA\&RB).

Tabel 4. Distribusi subjek penelitian berdasarkan jenis GTL Akrilik yang digunakan.

\begin{tabular}{lll}
\hline & $\mathrm{n}$ & $\%$ \\
\hline $\begin{array}{l}\text { Gigi Tiruan Satu Rahang } \\
\text { (RA-RB) }\end{array}$ & 45 & 75 \\
-(Gigi Tiruan RA) & $(38)$ & - \\
-(Gigi Tiruan RB) & $(7)$ & - \\
$\begin{array}{l}\text { Gigi Tiruan Dua Rahang } \\
\text { (RA \& RB) }\end{array}$ & 15 & 25 \\
\hline Total & 60 & 100 \\
\hline
\end{tabular}

Hasil penelitian pada Tabel 4 menunjukkan bahwa subjek penelitian yang menggunakan gigi tiruan pada satu rahang sebanyak 45 orang (75\%), yang terdistribusi masing-masing:Gigi tiruan RA sebanyak 38 orang $(63,3 \%)$ dan gigi tiruan RB sebanyak 7 orang (11,7\%). Subjek penelitian yang menggunakan gigi tiruan pada dua rahang (RA\& RB) sebanyak 15 orang (25\%).

Tabel 5 mendistribusikan jumlah GTL Akrilik yang digunakan oleh seluruh subjek baik RA atau RB.

Tabel 5. Distribusi subjek penelitian berdasarkan jumlah GTL Akrilik.

\begin{tabular}{lcc}
\hline Jumlah GTL Akrilik & $\mathrm{n}$ & $\%$ \\
\hline RA & 53 & 70,7 \\
RB & 22 & 29,3 \\
\hline Total & 75 & 100
\end{tabular}

Dari data ditribusi subjek penelitian berdasarkan jumlah GTL Akrilik pada tiap rahang yang digunakan oleh seluruh subjek, berjumlah 53 RA (70,7\%) dari hasil ini menunjukan bahwa subjek penelitian terbanyak menggunakan RA dan 22 RB (29,3\%).

Distribusi subjek penelitian berdasarkan lamanya pemakaian GTL Akrilik dan kondisi kebersihan GTL Akrilik, baik pada RA maupun RB menggambarkan keadaan klinis kondisi GTL Akrilik subjek penelitian dengan hubungan lamanya pemakaian GTL
Akrilik, dan hasil penelitian ini dapat dilihat pada tabel 6 dan tabel 7 .

Berikut ini merupakan tabel distribusi berdasarkan lama pemakaian serta kondisi kebersihan GTL Akrilik di RA yaitu:

Tabel 6. Distribusi subjek penelitian berdasarkan lamanya pemakaian dan kondisi kebersihan GTL Akrilik pada RA.

\begin{tabular}{|c|c|c|c|c|c|c|c|c|}
\hline \multirow{3}{*}{$\begin{array}{l}\text { Lamanya } \\
\text { pemakaian } \\
\text { GTLAkrilik }\end{array}$} & \multicolumn{6}{|c|}{ Kondisi Kebersihan GTL Akrilik } & \multirow{2}{*}{\multicolumn{2}{|c|}{ Total }} \\
\hline & \multicolumn{2}{|c|}{ Bersih } & \multicolumn{2}{|c|}{ Kotor } & \multicolumn{2}{|c|}{ Sangat kotor } & & \\
\hline & $\mathrm{n}$ & $\%$ & $\mathrm{n}$ & $\%$ & $\mathrm{n}$ & $\%$ & $\mathrm{n}$ & $\%$ \\
\hline $1<$ Tahun & 2 & 3,8 & 1 & 1,9 & - & 0 & 3 & 5,7 \\
\hline 1-5 Tahun & 15 & 28,3 & 11 & 20,7 & 7 & 13,2 & 33 & 62,2 \\
\hline 6-10 Tahun & 1 & 1,9 & 1 & 1,9 & 9 & 17 & 11 & 20,8 \\
\hline >10 Tahun & 1 & 1,9 & 2 & 3,8 & 3 & 5,7 & 6 & 11,3 \\
\hline Total & 19 & 35,9 & 15 & 28,3 & 19 & 35,9 & 53 & 100 \\
\hline
\end{tabular}

Hasil penelitian pada Tabel 6 menunjukkan bahwa, subjek yang menggunakan GTL Akrilik di bawah 1 tahun berjumlah 3 orang $(5,7 \%)$, subjek yang yang menggunakan GTL Akrilik yang berkisar antara 1 sampai 5 tahun berjumlah 33 orang $(62,2 \%)$. Hal ini menggambarkan bahwa sebagian besar subjek penelitian masih terbilang baru atau belum lama menggunakan GTL Akrilik. Selanjutnya subjek yang menggunakan GTL Akrilik dengan rentang waktu 6 sampai 10 tahun berjumlah 12 orang (20,8\%), dan subjek yang menggunakan GTL Akrilik yang lebih dari 10 tahun berjumlah 6 orang $(11,3 \%)$. Berdasarkan hasil pemeriksaan GTL Akrilik, kondisi kebersihan GTL Akrilik subjek penelitian pada umumnya dalam keadaan kotor.

Tabel 7. Distribusi frekuensi subjek penelitian berdasarkan lamanya pemakaian dan kondisi kebersihan GTL Akrilik pada RB.

\begin{tabular}{|c|c|c|c|c|c|c|c|c|}
\hline \multirow{3}{*}{$\begin{array}{l}\text { Lamanya } \\
\text { pemakaian } \\
\text { GTLAkrilik }\end{array}$} & \multicolumn{6}{|c|}{ Kondisi Kebersihan GTL Akrilik } & \multirow{2}{*}{\multicolumn{2}{|c|}{ Total }} \\
\hline & \multicolumn{2}{|c|}{ Bersih } & \multicolumn{2}{|c|}{ Kotor } & \multicolumn{2}{|c|}{ Sangat kotor } & & \\
\hline & $\mathrm{n}$ & $\%$ & $\mathrm{n}$ & $\%$ & $\mathrm{n}$ & $\%$ & $\mathrm{n}$ & $\%$ \\
\hline $1<$ Tahun & 2 & 9,1 & - & - & 3 & 13,6 & 5 & 22,7 \\
\hline 1-5 Tahun & 4 & 18,2 & 2 & 9,1 & 3 & 13,6 & 9 & 40,9 \\
\hline 6-10 Tahun & 1 & 4,5 & 3 & 13,7 & 2 & 9,1 & 6 & 27,3 \\
\hline$>10$ Tahun & - & - & - & - & 2 & 9,1 & 2 & 9,1 \\
\hline Total & 7 & 31,8 & 5 & 22,8 & 10 & 45,4 & 22 & 100 \\
\hline
\end{tabular}

Tabel 7 di atas menunjukkan bahwa subjek pengguna GTL Akrilik pada rahang 
bawah dengan waktu kurang dari satu tahun sebanyak 5 orang $(22,7 \%)$, sementara subjek yang menggunakan gigi tiruan antara 1 sampai 5 tahun sebanyak 9 orang (40,9\%), kemudian subjek yang telah menggunakan GTL Akrilik selama 6 sampai 10 tahun sebanyak 6 orang (27,3\%), dan subjek yang telah menggunakan GTL Akrilik lebih dari 10 tahun sebanyak 2 orang $(9,1 \%)$ dari hasil di atas dapat dilihat bahwa kondisi kebersihan GTL Akrilik subjek penelitian pada RB dilihat dari lamanya pemakaian GTL Akrilik.

Tabel 8 berisi data yang mendistribusikan subjek penelitian berdasarkan tempat pembuatan GTL Akrilik.

Tabel 8. Distribusi frekuensi subjek penelitian berdasarkan tempat pembuatan GTL Akrilik

\begin{tabular}{lrr}
\hline $\begin{array}{l}\text { Tempat } \\
\text { pembuatan gigi } \\
\text { tiruan }\end{array}$ & $\mathrm{n}$ & $\%$ \\
\hline Dokter gigi & 5 & 8,3 \\
$\begin{array}{l}\text { Tukang gigi } \\
\begin{array}{l}\text { Tekniker gigi } \\
\text { Mahasiswa } \\
\text { pendidikan } \\
\text { profesi }\end{array}\end{array}$ & 55 & 91,7 \\
\hline Total & - & - \\
\hline
\end{tabular}

Dari hasil penelitian pada Tabel 8 terlihat bahwa mayoritas masyarakat, yakni sebanyak 55 orang (91,7\%) subjek penelitian di Kelurahan Batu Putih Bawah membuat GTL Akrilik mereka pada tukang gigi. Sisanya sebanyak 5 orang $(8,3 \%)$ pada dokter gigi.

Hasil penelitian ini juga meliputi pemberian instruksi yang pernah di terima oleh subjek penelitian tentang pemeliharaan kebersihan pasca pemasangan GTL Akrilik baik instruksi secara lisan dan tulisan, pemeliharaan kebersihan GTL akrilik setiap hari yang dilakukan oleh subjek penelitian , frekusensi pembersihan GTL Akriik yang dilakukan oleh subjek penelitian dalam sehari, waktu pembersihan GTL Akrilik, cara pembersihan GTL Akrilik yang dilakukan oleh subjek penelitian, dan gambaran kondisi kebersihan GTL Akrilik secara umum yang digunakan oleh subjek penelitian data-data tersebut disajikan pada Tabel 9 hingga Tabel 15.

Tabel 9 berikut ini menyajikan distribusi frekuensi subjek penelitian berdasarkan instruksi lisan pasca pemasangan GTL Akrilik.

Tabel 9. Distibusi frekuensi subjek penelitian berdasarkan intrusksi lisan tentang caramembersihkan GTL Akrilik.

\begin{tabular}{lcc}
\hline Instruksi lisan & $\mathrm{n}$ & $\%$ \\
\hline Ya & 16 & 26,7 \\
Tidak & 44 & 73,3 \\
\hline Total & 60 & 100 \\
\hline
\end{tabular}

Tabel 9 menunjukkan bahwa sebagian besar, yakni sebanyak 44 subjek penelitian (73,3\%) tidak

Tabel 10 menyajikan tabel distribusi frekuensi subjek penelitian berdasarkan instruksi tulisan pasca pemasangan GTL Akrilik.

\begin{tabular}{|c|c|c|}
\hline Instruksi tulisan & $\mathrm{N}$ & $\%$ \\
\hline $\mathrm{Ya}$ & 3 & 5 \\
\hline Tidak & 57 & 95 \\
\hline Total & 60 & 100 \\
\hline
\end{tabular}

Hasil penelitian yang tampak pada tabel 10 menunjukkan bahwa mayoritas subjek penelitian, yakni sejumlah 57 orang (95\%) tidak mendapatkan instruksi dalam bentuk tulisan tentang cara membersihkan gigi tiruan pasca pemasangan dan hanya 3 orang (5\%) yang mendapatkan instruksi.

Tabel 11 menyajikan distribusi frekuensi subjek penelitian berdasarkan pemeliharaan kebersihan gigi tiruan setiap hari.

Tabel 11. Distribusi frekuensi subjek penelitian berdasarkan pemeliharaan kebersihan GTL Akrilik setiap hari.

\begin{tabular}{|c|c|c|}
\hline Setiap hari & $\mathrm{n}$ & $\%$ \\
\hline Ya & 57 & 95 \\
\hline Tidak & 3 & 5 \\
\hline Total & 60 & 100 \\
\hline
\end{tabular}

Data hasil penelitian pada Tabel 11 menunjukkan bahwa sebanyak 57 subjek penelitian (95\%) memelihara kebersihan 
gigi tiruannya setiap hari, sedangkan hanya 3 orang (5\%) yang tidak melakukan.

Tabel 12. Distribusi frekuensi subjek penelitian berdasarkan frekuensi pembersihan GTL Akrilik dalam sehari.

\begin{tabular}{|c|c|c|}
\hline Dalam sehari & $\mathrm{n}$ & $\%$ \\
\hline Sekali & 4 & 6,7 \\
\hline Dua kali & 39 & 65 \\
\hline Tiga kali & 17 & 28,3 \\
\hline Total & 60 & 100 \\
\hline
\end{tabular}

Tabel 12 memperlihatkan bahwa sebagian besar subjek penelitian, yakni 39 orang (65\%) membersihkan GTL Akrilik mereka dua kali sehari, sebanyak 17 orang (28,3\%) membersihkan GTL Akrilik tiga kali sehari, dan yang terkecil 4 orang (6,7\%) membersihkan GTL Akrilik sekali sehari.

Subjek membersihkan GTL Akrilik dengan waktu yang berbeda-beda. Tabel 13 berikut ini menyajikan distribusi frekuensi subjek penelitian berdasarkan waktu pembersihan GTL Akrilik dalam sehari.

Tabel 13. Distribusi frekuensi subjek penelitian berdasarkan waktu pembersihan GTL Akrilik.

Data pada Tabel 13 menunjukkan

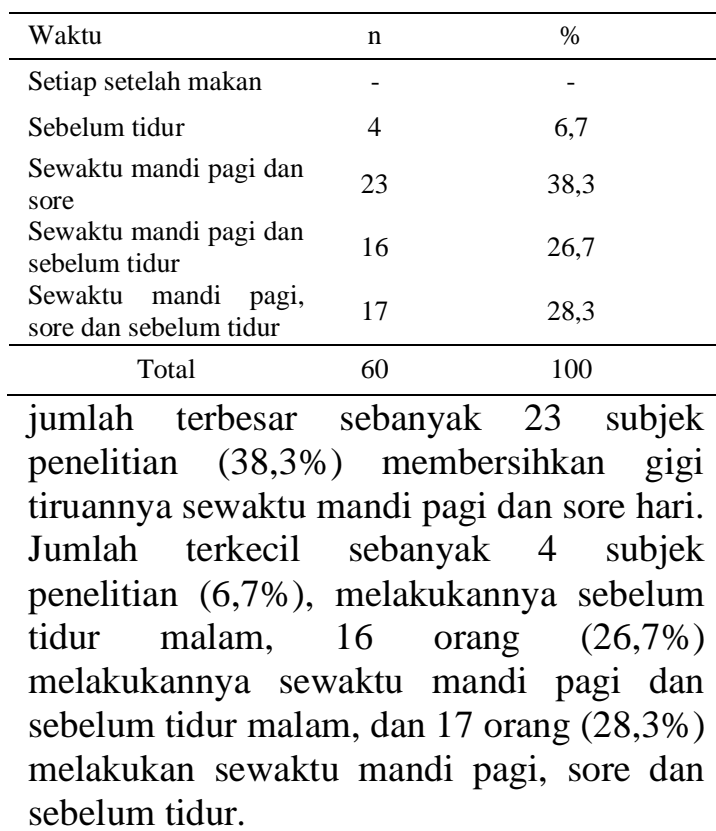

Tabel 14 mendistribusikan subjek penelitian berdasarkan cara yang dilakukan oleh subjek penelitian dalam membersihkan GTL Akriliknya. Cara pembersihan yang di maksud adalah subjek membersihkan GTL Akriliknya dengan menyikat menggunakan pasta gigi/sabun atau tidak menggunakan pasta gigi/sabun. Membersihkan GTL Akrilik dengan menggunakan pasta gigi/sabun atau tidak menggunakan pasta gigi/sabun dapat dilihat pada kondisi kebersihannya.

Tabel 14. Distribusi frekuensi subjek penelitian berdasarkan cara pembersihan GTL Akrilik.

\begin{tabular}{ccc}
\hline Cara & $\mathrm{n}$ & $\%$ \\
\hline Menyikat tanpa pasta gigi atau sabun & - & - \\
Menyikat pakai pasta gigi/sabun & 60 & 100 \\
\hline Total & 60 & 100 \\
\hline
\end{tabular}

Tabel 14 menunjukkan bahwa seluruh subjek penelitian, yakni 60 orang (100\%) membersihkan gigi tiruan dengan cara menyikat dengan pasta gigi/sabun.

Distribusi frekuensi subjek penelitian berdasarkan kondisi kebersihan GTL Akrilik yang digunakan oleh subjek dan disajikan pada Tabel 15.

Tabel 15. Distribusi subjek penelitian berdasarkan kondisi kebersihan GTL Akrilik.

\begin{tabular}{|c|c|c|}
\hline Kondisi & $\mathrm{n}$ & $\%$ \\
\hline Bersih & 20 & 33,4 \\
\hline Kotor & 19 & 31,6 \\
\hline Sangat kotor & 21 & 35 \\
\hline Total & 60 & 100 \\
\hline
\end{tabular}

Data hasil penelitian pada Tabel 15 menunjukkan bahwa mayoritas kondisi GTL Akriliknya kotor, dimana jumlah terbesar yakni 21 subjek penelitian (35\%) memiliki GTL Akrilik yang kondisinya sangat kotor dan 19 subjek penelitian $(31,6 \%) \quad$ kondisinya kotor. Subjek penelitian yang memiliki GTL Akrilik yang kondisinya bersih hanya sebagian kecil, yakni 20 orang $(33,4 \%)$.

\section{BAHASAN}

Hasil penelitian yang diperoleh menunjukkan bahwa mayoritas masyarakat pengguna GTL Akrilik tidak pernah mendapatkan instruksi secara lisan maupun tulisan pasca pemasangan GTL Akrilik. Peneliti berpendapat bahwa hasil ini bisa 
dimaklumi, karena hampir semua subjek membuat GTL Akriliknya di tukang gigi. Tukang gigi tidak memperoleh pendidikan secara formal tentang kesehatan gigi dan mulut, dan umumnya pengsetahuan mereka hanya terbatas pada ketrampilan teknik pembuatan gigi tiruan saja. Keterampilan ini mereka peroleh secara informal. Dalam pelayanannya, tukang gigi lebih mementingkan segi bisnisnya, bukan pelayanan kesehatan sehingga urusan dengan pasien lebih ke arah hubungan "penjual" dan "pembeli". Di samping itu tukang gigi cenderung kurang memerhatikan kondisi kesehatan para pengguna GTL Akrilik, dikarenakan ketidaktahuan mereka. Hal ini tergambar dari minimnya informasi yang diberikan pasca pemasangan yang dilakukan oleh tukang gigi tersebut.

Masyarakat di Kelurahan Batu Putih Bawah kecamatan Ranowulu Bitung Utara, umumnya berprofesi sebagai nelayan dan petani. Hasil penelitian tentang perilaku responden dalam pemeliharaan kebersihan GTL Akriliknya menunjukkan 95\% subjek membersihkan GTL Akriliknya setiap hari, dimana 39 di antaranya (65\%) subjek membersihkan GTL Akriliknya dengan frekuensi dua kali sehari dan 17 subjek $(28,3 \%)$ bahkan memiliki frekuensi penyikatan/pembersihan GTL Akriliknya hingga tiga kali sehari. Peneliti berpendapat hasil ini bisa saja benar demikian, atau bisa juga bukan merupakan gambaran yang sebenarnya. Apabila hasil ini merupakan gambaran sebenarnya dari kondisi yang ada, menunjukkan bahwa pengguna GTL Akrilik sudah memiliki perilaku yang benar dalam pemeliharaan gigi tiruan yang digunakan oleh para subjek.

Apabila hasil ini bukan merupakan kondisi yang sebenarnya, peneliti berasumsi bahwa subjek tidak jujur dalam menjawab pertanyaan yang diajukan peneliti melalui kuesioner. Alasan subjek tidak jujur mungkin dikarenakan subjek merasa malu untuk mengatakan yang sebenarnya, padahal pemeliharaan kebersihan GTL Akrilik yang digunakan belum dilakukan secara benar sehingga hasilnya tidak maksimal. Hal ini bisa dibuktikan nanti dari hasil pemeriksaan kondisi GTL Akrilik yang bersangkutan.

Dalam memelihara kebersihan GTL Akrilik yang digunakan, faktor waktu ikut memegang peranan penting. Hasil penelitian menunjukkan bahwa sebagian besar subjek (38,3\%) membersihkan GTL Akriliknya sewaktu mandi pagi dan sore hari. Gambaran ini memperlihatkan bahwa perilaku para pengguna gigi tiruan dalam pemeliharaan GTL Akrilik umumnya belum benar. Sewaktu mandi pagi mereka menyikat GTL Akriliknya, kemudian dilanjutkan dengan sarapan. GTL Akriik tidak dibersihkan hingga menjelang sore hari.

Akumulasi sisa makanan yang menempel sejak pagi hari hingga menjelang sore hari menyebabkan kondisi GTL Akrilik dalam keadaan kurang bersih, karena mayoritas subjek (38,3\%,) menyikat gigi sewaktu mandi pagi dan sore. Subjek beralasan tidak membersihkan GTL Akriliknya setelah waktu makan oleh karena alasan ketidakpahaman. Keadaan GTL Akrilik yang kotor ini bertahan hingga saatnya mandi sore. Saat selesai makan malam, kondisi GTL Akrilik kembali kotor hingga menjelang mandi pagi hari, hal ini diperparah dengan kondisi GTL Akrilik yang tetap dipertahankan dalam mulut saat tidur malam.

Berdasarkan wawancara dengan Subjek, beragam alasan dikemukakan subjek sebagai dalih atau alasan untuk tetap menggunakan GTL akrilik pada malam hari. GTL Akrilik tetap dipertahankan dalam mulut karena merasa tidak nyaman saat gigi tiruan dilepas dari rongga mulut, atau berdalih merasa tidak nyaman saat memasangnya kembali di mulut.

Seperti layaknya gigi asli, GTL Akrilik juga perlu disikat setiap hari untuk membersihkan GTL Akrilik dari sisa makanan dan plak yang menempel pada permukaan GTL Akrilik. Pada penelitian ini semua subjek atau 60 orang subjek penelitian (100\%) mengaku membersihkan GTL Akriliknya dengan cara menyikat dengan pasta gigi/sabun. Jika responden menyikat GTL Akriliknya dengan pasta gigi/sabun, tentunya kebersihan gigi tiruan subjek akan terjaga. Namun jawaban subjek 
belum sepenuhnya dapat dipercaya, harus dilihat keberadaan GTL Akrilik yang digunakan. Kalau cara pemeliharaan kebersihannya sudah benar, tentunya akan tampak pada kondisi GTL Akrilik subjek tersebut.

Hasil penelitian memperlihatkan bahwa kondisi GTL Akrilik subjek umumnya kotor. Bila dibandingkan dengan jawaban yang diberikan subjek berkaitan dengan cara yang digunakan untuk memelihara kebersihan gigi tiruannya terlihat kontradiktif. Data yang ada menunjukkan 95\% subjek mengaku membersihkan GTL Akriliknya setiap hari. Sebagian besar (65\%) subjek membersihkan GTL Akriliknya dengan frekuensi dua kali sehari, bahkan ada subjek yang sampai tiga kali sehari membersihkan GTL Akriliknya (28,3\%). Penulis berasumsi dengan perilaku menjaga kebersihan seperti ini, akan memberikan hasil gambaran berupa kondisi gigi tiruan yang bersih. Kenyataan yang ada kondisi GTL akrilik subjek kotor, dan bahkan ada yang sangat kotor; atau dengan kata lain sebagian besar GTL Akrilik yang digunakan subjek kondisinya kotor.

Kondisi GTL Akrilik subjek yang umumnya kotor dipengaruhi oleh waktu penyikatan yang tidak tepat, karena mayoritas subjek (38,3\%) menyikat gigi tiruan sewaktu mandi pagi dan sore, hal ini keliru. Waktu yang tepat untuk membersihkan gigi tiruan adalah segera setelah makan dan sebelum tidur malam. Kondisi GTL Akrilik yang umumnya kotor ini dipengaruhi juga oleh tingkat pengetahuan subjek. Subjek umumnya adalah lulusan SLTP yang tingkat pengetahuannya masih minim. Pengetahuan yang mereka miliki dalam kaitannya dengan kesehatan gigi dan mulut umumnya diperoleh dari lingkungan keluarga. Penyebab lainnya karena kurangnya informasi dari tukang gigi tentang pentingnya pemeliharaan kebersihan gigi tiruan yang digunakan oleh subjek.

Menurut hasil sebuah penelitian yang dilakukan Ridwan. L, Liana .R, Lady Y. H. di Aceh pada tahun 2010, mengatakan bahwa perawatan gigi tiruan memiliki perbedaan menurut tingkat pendidikan seseorang, karena setiap orang mempunyai tujuan, motivasi dan pengetahuan yang berbeda pula. Tingkat pendidikan seseorang sangat berpengaruh pada perawatan gigi tiruan, dikarenakan tingkat pendidikan berpengaruh langsung pada kesadaran. Pengetahuan seseorang sangat berdampak dalam keputusan untuk menggunakan gigi tiruan atau tidak, termasuk juga pada perilaku dalam memelihara kebersihan gigi tiruan yang digunakannya.

Menurut hasil penelitian di Kelurahan Batu Putih Bawah, subjek yang menggunakan gigi tiruan terbanyak tingkat pendidikannya pada jenjang SLTP yaitu sejumlah 36,6\%, dan tingkat pendidikan pada jenjang SD, yaitu 30\%. Hal ini menggambarkan bahwa tingkat pendidikannya umumnya masih rendah sehingga pengetahuan yang dimiliki juga sangat minim. Menurut Ridwan. L, dkk, individu dengan tingkat pendidikan yang lebih tinggi akan lebih peduli pada kesehatan gigi tiruan dan mulutnya dibandingkan dengan individu dengan tingkat pendidikan yang lebih rendah. Alasannya adalah orang dengan tingkat pendidikan lebih tinggi, lebih banyak memiliki informasi dan pengetahuan termasuk pengetahuan tentang kesehatan gigi dan mulut.

Orang dengan tingkat pendidikan yang lebih tinggi juga, umumnya memiliki tingkat ekonomi yang lebih tinggi dibandingkan dengan orang yang tingkat pendidikannya lebih rendah. Hal ini seperti menjadi sebuah batasan bagi orang yang memiliki tingkat pendidikan yang rendah, karena selain mengalami kekurangan dari segi ekonomi mereka juga sulit untuk mendapatkan informasi, pengetahuan, bahkan pelayanan kesehatan yang baik.

Kesehatan gigi dan mulut terlebih khusus pada pengguna gigi tiruan, dipengaruhi juga oleh kebersihan gigi tiruan. Kebersihan GTL Akrilik yang digunakan memiliki peranan penting dalam mencegah terjadinya beberapa penyakit rongga mulut. ${ }^{8}$ GTL Akrilik yang bersih merupakan modal untuk mendapatkan kesehatan rongga mulut dan juga bisa meningkatkan kepercayaan diri seseorang. Individu dengan tingkat pendidikan yang 
lebih tinggi, akan lebih mementingkan faktor estetik serta kebersihan gigi tiruan yang digunakan, namun bagi kebanyakan masyarakat dengan tingkat pendidikan yang lebih rendah, terkadang faktor estetik dan kebersihan gigi tiruan dianggap tidak begitu penting, sehingga kebersihan gigi tiruannya kurang diperhatikan.

GTL Akrilik yang tidak terjaga kebersihannya dapat menyebabkan berbagai penyakit dalam rongga mulut. GTL Akrilik yang tidak bersih dapat menyebabkan penumpukan plak, yang berpotensi menyebabkan berbagai penyakit pada rongga mulut. Sampai saat ini masih banyak masyarakat termasuk pengguna gigi tiruan di Indonesia yang mengalami penyakit jaringan penyangga gigi dan karies gigi, sumber dari kedua penyakit tersebut akibat terabaikannya kebersihan gigi dan mulut. ${ }^{9}$ Masalah lainnya yang berkaitan dengan kebersihan gigi tiruan yaitu berupa infeksi kandida yang merupakan masalah yang umum terjadi pada pasien dengan GTL Akrilik. Bentuk infeksi tersering ialah denture stomatitis. Infeksi lainnya yang disebabkan oleh jamur candida pada pasien dengan Gigi Tiruan Lepasan, yaitu candida leukoplakia. ${ }^{10}$ Prevalensi pengidap stomatitis pada pemakai gigi tiruan semakin tinggi jika pengguna gigi tiruan memiliki gaya hidup yang tidak sehat, atau tidak bisa menjaga kebersihan gigi tiruannya. ${ }^{11}$ Faktor kebiasaan buruk bisa menjadi penyebab penyakit pada pengguna gigi tiruan, meskipun gigi tiruan hanya alat bantu untuk mengganti gigi asli yang sudah hilang, tapi kebersihan gigi tiruan juga harus tetap dijaga dan diperhatikan.

Kebersihan gigi tiruan menjadi kewajiban semua orang yang menggunakan gigi tiruan, baik dengan tingkat pendidikan yang tinggi maupun dengan tingkat pendidikan yang lebih rendah. Peranan pemerintah dan petugas kesehatan sangat diperlukan agar pelayanan kesehatan bisa terlaksana dengan maksimal, karena semua masyarakat berhak mendapat pelayanan kesehatan yang setara. Masyarakat yang tinggal di daerah terpencil atau masyarakat yang jauh dari kota perlu mendapatkan perhatian, sehingga akses untuk mendapatkan pelayanan kesehatan lebih mudah. Perkembangan yang sangat pesat seperti saat ini seharusnya menjadi momentum dalam perkembangan pelayanan kesehatan bagi seluruh masyarakat yang membutuhkan pelayanan yang berkualitas serta mencakup setiap elemen masyarakat.

Peningkatan pelayanan kesehatan, akan berdampak baik bagi masyarakat pengguna GTL Akrilik yang berada di daerah yang pengetahuan tentang kebersihan gigi tiruannya kurang, seperti di Kelurahan Batu Putih Bawah. Dengan adanya peningkatan pelayanan kesehatan, diharapkan pengetahuan dan perilaku masyarakat dapat lebih meningkat, karena dengan semakin tinggi pengetahuan masyarakat pengguna GTL Akrilik, maka masyarakat akan lebih sadar dan mengerti tentang cara memelihara kebersihan GTL Akrilik yang mereka gunakan. Jika masyarakat pengguna gigi tiruan sudah mengerti tentang cara pemeliharaan kebersihan GTL Akrilik dan bisa menerapkannya dalam kehidupan seharihari, tentunya kualitas hidup dan status kesehatan masyarakat di Kelurahan Batu Putih Bawah akan meningkat.

Meningkatnya kulitas hidup dan status kesehatan masyarakat, akan memberikan efek positif dalam kehidupan masyarakat, karena masyarakat yang sehat adalah masyarakat yang sadar akan kebersihan. Diharapkan dengan meningkatnya pelayanan kesehatan, masyarakat akan menjadi lebih bertanggung jawab dalam menjaga kebersihan gigi dan mulut, terutama GTL Akrilik yang mereka gunakan dan bisa menjadi contoh bagi pengguna GTL Akrilik yang lain. Sehingga peningkatan pengetahuan tentang pemeliharaan kebersihan GTL Akrilik bisa memacu masyarakat agar lebih peduli dengan kebersihan GTL Akrilik. Sesuatu yang besar dimulai dari hal kecil, begitu pula dengan kebiasaan menjaga kebersihan GTL Akrilik, yaitu dimulai dari diri sendiri, sehingga bisa menjadi panutan bagi pengguna GTL Akrilik yang lain.

\section{SIMPULAN}

Berdasarkan hasil penelitian diperoleh umumnya responden di Batu Putih Bawah 
mempunyai kondisi klinis GTL akrilik yang kotor.

\section{SARAN}

1. Bagi Masyarakat

Dengan penelitian ini kiranya masyarakat pengguna GTL Akrilik di Kelurahan Batu Putih Bawah kecamatan Ranowulu Bitung utara dapat menyadari tentang menjaga kebersihan GTL Akrilik yang digunakan.

2. Bagi Pemerintah dan Tenaga kesehatan

Sangat diharapkan agar pemerintah bersama tenaga kesehatan atau tenaga medis dapat melakukan kegiatan penyuluhan berbasis masyarakat khususnya pada pengguna gigi tiruan tentang pemeliharaan kebersihan gigi tiruan yang benar, dan juga kiranya dapat memberikan pelayanan kesehatan gigi dan mulut di daerah tersebut.

3. Bagi institusi dan Peneliti

Perlu dilakukan penelitian lebih lanjut dengan cara pengambilan sampel dan metode yang berbeda, untuk mendapat hasil yang lebih luas dan dapat menjadi patokan pada penelitian-penelitian yang akan datang.

\section{DAFTAR PUSTAKA}

1. Peracini. A, Andrade de. M. I. Behaviors and hygiene habits of complete denture wearers. Braz Dent J. 2010. P. 247-252.

2. Hartono R, Kosasih A, Hidayat H, Morganelli C. J. Estetik \& prostetik mutakhir kedokteran gigi. Jakarta: EGC. 1992. Hal. 12-13,38.

3. Harsoyo. Y, Rubiyanto.P A. Ideologi koperasi: Menatap Masa Depan.
Cetakan 1. Yogyakarta.: Pustaka widyatama; 2006. Hal. 91-92.

4. Agniti. D. M. Presentase pengguna protesa di Indonesia. Media Litbang Kesehatan Volume XX. Nomor 2 Tahun 2010. Hal. 50-58.

5. Pattanaik. S, BVJ. Vikas. Denture stomatitis: A Literature Review. Journal of Indian Academy of Oral Medicine and Radiology. 2010. P. 136-140.

6. Sipayung I. B. Kebiasaan memelihara kebersihan gigi tiruan pada masyarakat pemakai gigi tiruan sebagian lepasan di kelurahan Tanjung Rejo kecamatan Medan Sunggal Tahun 2012. Skripsi; Medan. 2012. Hal. 1.9-30.

7. Lidan R, Rahmayani L, Hikmah Y. L. Hubungan jenis kelamin dan tingkat pendidikan terhadap penggunaan gigi tiruan sebagian lepasan di praktek dokter gigi spesialis prostodonsia. Cakradonya Dent J 2011. Hal. 332339.

8. Tarigan. S. Pasien Prosthodonsia lanjut usia: Beberapa pertimbangan dalam perawatan. USU 2005. Hal. 4-6.

9. Anitasari S, Rahayu E. N. Hubungan frekuensi menyikat gigi dengan tingkat kebersihan gigi dan mulut siswa sekolah dasar negeri di kecamatan Palaran kotamadya Samarinda provinsi Kalimantan Timur. Dent. J. Vol. 38. No. 2 April-Juni 2005. Hal. 88-90.

10. Paskalis S, Irmagita A. Candidal leukoplakia on patient with removable denture. Journal of Dentistry Indonesia Vol. 19, No. 2. 2012. P. 47-50.

11. César L, De Souza C. L, Lorenzo E, Jorge D, Angela P. Denture hygiene: importance in denture stomatitis control. Rev Gaúcha Odontol. Porto Alegre. 2013. P. 255-261. 